\title{
Conservation by Captive Breeding: a General Survey
}

\author{
By Richard Fitter
}

Breeding rare animals in captivity is only a second best but essential if they cannot be preserved in the wild, and in this zoos have an important part to play. Richard Fitter, hon. secretary of the Fauna Preservation Society, describes some of the most successful captive breeding programmes so far-Père David's deer, European bison, Przewalski wild horse and Arabian oryxand urges zoos to give serious attention now to the more difficult tasks of breeding primates and carnivores, of which several species, notably orang utans and the larger apes are endangered. He also suggests that zoos should anticipate the day when species now common become rare by establishing captive breeding programmes that would make them self-supporting in these animals.

IN THE 50 years since the San Diego Zoo was founded, approximately 50 birds and 50 mammals, which might be on exhibit here today, have vanished off the face of the earth. And the process continues. Peter Scott has described our IUCN Red Data Book. In its two volumes are listed the 277 species or subspecies of mammals, and 259 species or subspecies of birds which are so rare that they are in serious danger of becoming extinct. There are also at least 60 or 70 mammals and many birds that still have to be put into the book, and as many other animals continue to enter the danger zone year by year still more will have to be added. It has been calculated that at least one species or subspecies of both mammals and birds becomes extinct every year. We in the Survival Service Commission are now working on reptiles, fish and all the lesser animals whose status we have scarcely begun to know about. We do, however, have a pretty good idea of the causes of this perpetual drain on the fauna of the globe, and most of them come back to that highly aggressive and successful species which is filling this hall at this moment: manyou and me.

Man kills animals directly, either for sport or for food, or because he considers them, often quite wrongly, to be pests or in some way harmful to his material interests. Man kills animals indirectly in many ways, but mainly by destroying their habitat and food supply. While we drain marshes, fell forests, and build dams, cities and concrete highways, we cannot, in our present state of knowledge, say whether direct or indirect causes are the more lethal in actually exterminating animals; they are probably equally important. The Arabian oryx, for example, is threatened by direct killing for sport, the whooping crane by being accidentally shot in mistake for other cranes, the black 
rhinoceros by the destruction of its habitat, the Asiatic rhinos by slaughter for the sake of the alleged aphrodisiac qualities of their horns, and the orang utan and monkey-eating eagle because they have had the misfortune to become status symbols, the one as a pet, and the other as an ornament.

We are faced with this seemingly hopeless situation, in which the wild fauna of the world appears to be sliding, at varying speeds, down the slippery slope to final extinction. Some people simply throw up their hands and say that wild animals are doomed, and we cannot or must not obstruct the march of progress. But I like to think that this is not an attitude which appeals to the optimistic temperament of the American people. For after all we have a pretty good idea of what needs doing, and there are several practical ways of averting the multiple threats to wildlife.

Obviously the most satisfactory method is to preserve and protect the animals in their natural habitat, if necessary in national parks and sanctuaries of various kinds, and of course the larger the areas of wilderness that can be enclosed the better. When, however, this is not possible, the next best thing, and indeed the only practical alternative, is to preserve them in breeding colonies in zoos or zoological parks, or even in private collections, until such time as they can safely be released again in the wild. San Diego is a particularly appropriate place in which to embark on a discussion of the practical ways of saving animals, because this superb zoo has a splendid record in maintaining breeding stocks of many different kinds of rare animals, such as the Galapagos tortoise and the great apes.

\section{Zoos Should Specialise}

The breeding of rare animals in zoos was one of the four main themes of the "Zoos and Conservation" symposium held at the London Zoo in June 1964 under the auspices of the IUCN, ICBP, and IUDZG (International Union of Directors of Zoological Gardens). That meeting concluded that every encouragement should be given to the breeding of wild animals in captivity in order to reduce the demands on wild stocks, but that this calls for careful control of both the capture and transport of the original stock, and equally careful scientific and veterinary management once the animals have been received in captivity. The London meeting also concluded that greater specialisation among zoos would help to make better use of limited breeding material, or in other words, that each zoo should select one or a few rare species which it is particularly fitted to breed, and concentrate on them. It is obviously stupid to leave solitary animals languishing in widely scattered zoos, and one of the aims of the Wild Animal Propagation Trust in the USA is to enable rare strangers to meet one another. This also is why the London Zoo magnanimously sent their female Arabian oryx, Caroline, to join the World Herd at Phoenix, Arizona. 
Another recommendation of the London symposium was that a code of rules and standards for zoos and other institutions owning and breeding rare and endangered species should be prepared. So far as I know, nothing has yet been done to implement this particular suggestion, although the Survival Service Commission has taken over the co-ordination of the maintenance of stud books for rare species bred in captivity. Caroline Jarvis will speak about this later on. For instance, the San Diego Zoo has taken on the addax, and my own Society, the Fauna Preservation Society, has been asked to maintain the records for the Arabian oryx.

Pere David's Deer

The classic instance of the saving of a rare animal by breeding in captivity is that of Père David's deer, or Mi-Lu to give it its Chinese name. The story has often been told of the discovery in 1865 of this deer, hitherto unknown to science, when the French explorer Armand David succeeded in being the first foreigner to see what lay inside the 45-mile wall of the Imperial Hunting Park of Nan-Hai-Tsoe just south of Peking. David realised at once that this strange large deer with a donkey-like tail was something new, and managed to bribe the Tartar guards to let him have a specimen, which was duly transported to Paris.

The Mi-Lu, which has since been found in sub-fossil deposits, perhaps became extinct in the wild some two or three thousand years ago. Just how it came to be preserved in the Imperial Hunting Park we do not know, and probably we never shall know. Later, British and French diplomats managed to get some live specimens of this deer out to European zoos. This was a most fortunate thing because in 1895 the park wall was breached by a flood and all but a score of the deer escaped and were either drowned or slaughtered by starving peasants. In 1900 the foreign troops engaged in quelling the Boxer Rebellion virtually exterminated the remaining stock in the park, so that within a few years this deer actually became extinct in China. However, at this point, the eleventh Duke of Bedford, grandfather of the present Duke, stepped in and gave us the prototype of the sort of operation we are now discussing. He managed to persuade the European zoos to let him collect together all the available specimens in his magnificent park at Woburn Abbey in Bedfordshire, England, to a total of 18. By the outbreak of World War I he had built his herd up to 88 beasts, and from the 50 that survived the privations of that war, when the Duke was forbidden to buy extra winter feed for them, he and his successors raised the total to some 200 by the outbreak of World War II and doubled the figure within a few years of the war's end.

By now it was time to stop keeping all the eggs in one basket, especially as a single outbreak of foot-and-mouth disease, for which the slaughter policy for infected beasts is inflexible in Britain, might have demolished the work at a single blow. Accordingly, breeding herds and nuclei of Père David's deer have been established first at the nearby Whipsnade Park Zoo of the Zoological Society of London, 
and later at more than 30 zoos and collections throughout the world. The stud book for Père David's deer is kept at Whipsnade Zoo. A photograph of these deer is on plate 14 following page 116.

The closest parallel to Père David's deer, of an animal never known to science except in captivity in a park, is provided by the Chillingham wild white cattle at Chillingham Park in Northumberland, England. These used to be thought of as descendants of the aurochs or ancient wild ox of Europe, but more recent research suggests that they may have originated in Italian domestic cattle imported by the Romans. There are some suggestions that they were originally some kind of sacred cattle used for religious ceremonies and that that is why they were kept within a park. They have now been emparked at Chillingham since at least the mid 14th century and probably much earlier; they have become completely wild and are virtually unapproachable. There are a number of other herds of wild white cattle in Britain notably those at Chartley in Staffordshire (now removed to Woburn Park and Whipsnade Zoo, at Dynevor and Vaynol in Wales, and at Cadzow in Lanarkshire, Scotland, but they are distinguished from the Chillingham Cattle by having black instead of red ears.

\section{The Przewalski Horse}

Another mammal whose survival depends almost wholly on captive stocks is Przewalski's horse, Equus przewalskii. At the beginning of the last century it was thought that no genuine wild horses survived, all known herds supposedly being feral. Although an Englishman reported that Cossack officers whom he had met in Paris in 1814, knew of genuine wild horses in Mongolia, he was not believed and it was not until the Polish explorer Przewalski discovered them in 1879 (the horses were named after him despite the fact he at first maintained that they were asses) that they were brought within the purview of zoologists. This Mongolian stock may still survive, although in small numbers, and in so remote a spot that nobody can be quite sure whether they still do exist or not.* Fortunately again, some specimens were brought to Europe and herds were established at two famous collections, Askaniya Nova, in the Ukraine, and Woburn Abbey, home of the Père David's deer. Both of these, however, have died out and the present world stock of 110 animals originated entirely from two small herds, each about a dozen strong, which survived at the Prague and Munich Zoos in 1950. The stud book for Przewalski's horse is kept by the Prague Zoo. A photograph is on plate 7, following page 116.

This is perhaps the place to mention the remarkable experiments by the Heck brothers at Munich and Berlin Zoos, whereby they have bred back from existing domestic stock animals closely resembling, and perhaps virtually identical with, the tarpan, which was the European forest form of the Przewalski horse, and the aurochs or ancient wild ox of the European forests. The tarpan had become extinct as recently

* In ORYX, December, 1966, an account of a new sighting of Przewalski's horses in western Mongolia in the summer of 1966 , is described by Dr. Z. Kaszab. Editor. 
as 1919, when the last one died in captivity, but the aurochs became extinct more than 300 years ago, and we only know what it looks like from an old print discovered in a book of the early 17 th century. It must not be deduced from these experiments, however, that it is all right to allow animals to become extinct because they could always be bred back again. Such a thing is only possible with a handful of species which have been domesticated, and even so, it is impossible to say more than that we have got an animal that is remarkably similar to what we have lost. What we have got in this case is an animal remarkably similar to a picture in a book published in 1620 , which is a remarkable achievement. We have got back a true-breeding strain that looks something like it.

\section{The European Bison}

With the European bison or wisent Bison bonasus, now extinct in the original wild stock, it has been possible to advance to the next stage, which is to release some into the wild again. That is what we are aiming at all the time. The European bison was once widespread in the forests of Europe, but its range gradually became more restricted until by the end of the last century it was virtually confined to the Bialowieza Forest, in eastern Poland, and to the foothills of the Caucasus. In both these places World War I and its turbulent aftermath put an end to the original wild stock which appears to have perished finally in the 1920's.

Fortunately once again the species survived in captivity, and in 1923 the International Society for the Protection of the European Bison was formed in order to resuscitate it. Nine years later it was possible to publish the first Pedigree Book of the European Bison, in which 30 pure-bred beasts were recorded. World War II proved less disastrous for the bison, and the post-war edition of the Pedigree Book listed 98 pure-bred animals in various European zoos. Today the overall figure may be as high as 800 , and a start has been made with restoring the European bison to the wild, most appropriately in its old home in the Bialowieza Forest, where 57 now live in the wild state, 34 of them actually born in the wild. Two bison need about 1000 hectares to live in, and Bialowieza is potentially able to take 110 to 115 specimens. However, there appear to be no other forests left in Europe, outside the Soviet Union, that are suitable for reacclimatising bison.

Work in the USA

The success of breeding these three rare and endangered ungulates Père David's deer, Przewalski's horse, and the European bison, in captivity or semi-captivity, has encouraged attempts with other ungulates at an earlier stage than the verge of extinction, and I need only mention Askaniya Nova in Russia, the Catskill Game Farm in New York State, and the various ranches in Texas and California where African ungulates are currently being kept and bred successfully.

It was with very great interest that we in England learned of the vigorous efforts being made by the Bureau of Sport Fisheries and 
Wildlife to establish breeding stocks of the rarer North American wildlife at their Patuxent station in Maryland. Last May Peter Scott and $I$ had the great pleasure of being shown the early stages of this important work by John Gottschalk, and last week I learned that they have had a most successful season with their Aleutian geese. Similar work is in progress in New Zealand with some of that country's rare birds, but with little success so far. There are, of course, quite a number of instances of rare animals, almost always ungulates, being saved by the protection of small surviving stocks in national parks. The story of the American bison in well known to you all, but I must mention the successful attempts to save the bontebok, a species of antelope, and the Cape mountain zebra in small national parks in South Africa. The bontebok is kept on private farms as well as in parks and reserves. Only 35 years ago its numbers were reduced to 17; today there are around 750-a further indication that so long as a handful of breeding pairs remain it is worth trying to establish a captive breeding herd.

\section{The Arabian Oryx}

There is, of course, one other well known and very recent instance of the establishment of a captive breeding herd in order to save an ungulate in danger of extinction, and that is the Arabian oryx with which my own Society, the Fauna Preservation Society, is especially associated as the organisers of the original Operation Oryx in 1962; Major Grimwood, leader of the expedition, is here himself to speak about it. The World Herd of Arabian oryx was established at Phoenix Zoo, Arizona, and now consists of 16 animals, half of which were actually born at Phoenix. As Peter Scott told you, he and I had the very great pleasure of seeing these animals a few days ago. This experience was a great satisfaction indeed, and we are enormously grateful to all those on this side of the Atlantic who have worked so hard to ensure this happy outcome. With the Arabian oryx we have already got to the stage where we feel we should think in terms of establishing further breeding centres on both sides of the Atlantic, and we can look further into the future towards the possibility of eventually re-establishing this fine antelope in a part of its range where it has been extinct for a good many years, perhaps first in one of the new national parks of Jordan.

All these species that I have now mentioned are the most successful of the various captive breeding schemes for rare and endangered animals, and it will not have escaped your notice that they are all ungulates, or hoofed animals. Ungulates are without a doubt the easiest of the larger mammals to breed in captivity, and we should certainly be thinking forward and deciding which other ungulates we could start saving in this way. For instance, I think we should take a hard look at the tamarau, the wild ox of the Philippines, which will certainly become extinct quite soon if nothing is done to save it from poachers. The various races of the wild ass, such as the onager in 
Iran and the Indian and Somali wild asses are in great danger, and so is the now extremely rare Persian fallow deer. This last was the object of an expedition by the Iranian Game Department last January, aided by a grant from the Joint Revolving Fund of the Fauna Preservation Society and the World Wildlife Fund. Unfortunately, on this occasion severe flooding forced the suspension of the attempt before any deer could be caught, but a nother attempt is planned for this coming winter.

\section{The Case for the Primates}

Whether captive breeding on this scale will ever be so successful with other endangered mammals such as some of the primates and carnivores is more doubtful, but in the case of the primates at least we shall have to make the attempt, otherwise we stand to lose several species. It has been shown that all the larger apes can be bred in captivity, and it seems to me it is now up to the zoos to come together so that within say five or ten years they can breed all their own apes and cease making demands on the rapidly diminishing wild stocks. The present methods of capturing apes are immensely wasteful, with up to six or eight wild individuals perishing for every one that finally reaches a zoo, and it is particularly important that zoos should tackle this one. With some animals, it is arguable that the wild stocks can be culled to provide zoo stocks more or less indefinitely, but this does not apply to the larger apes. We should also look into the possibility of establishing feral breeding colonies of monkeys, and also of apes, such as those which have so successfully been established on certain of the West Indian islands.

Success with Birds

Of course, this technique of establishing captive breeding stocks applies to many other animals besides the larger mammals. With rodents it can be notably successful, as witness the raising of all the hundreds of thousands of golden hamsters now existing in captivity all over the world from a single gravid female found in the Lebanon some 35 years ago. So far as I know, nobody has even seen a golden hamster in the wild before or since. With birds too this method can be applied, and today we have with us, in our Chairman, one of the people responsible for the notably successful captive breeding of the ne-ne, or Hawaiian goose, and its re-establishment on the island of Maui. I will leave it to him to tell this story himself. The Laysan teal is another bird that needs to be tackled in this way, although its story is rather different from that of the ne-ne goose which was in grave danger of extinction in its native habitat. The trouble with the Laysan teal is that its native habitat is too small, and we need to provide some other outlets for it.

In England the Ornamental Pheasant Trust has similar aims with regard to the rarer game birds, and has already bred up sufficient numbers of the very rare Swinhoe's pheasant from Taiwan to con- 
template an attempt to restore some of their native forests." A few pairs of this species are also to be released on Brownsea Island in Poole Harbour, Dorset, England, in the hope of establishing a feral breeding stock there.

\section{Species in which Zoos could be self-supporting}

I was asked to talk about the importance of zoos in breeding rare animals, but $I$ must also say a few words about the equal, in some ways even the greater, importance of zoos breeding their own stocks of commoner animals. Although for many years to come zoos will be able to draw on the natural surplus of most wild animal stocks for their own supplies, it cannot be assumed that this situation will last for ever, particularly with those species, notably the great apes and carnivores, where heavy losses are experienced in the process of capture and in the early stages of captivity. It is perfectly possible that many common zoo animals will become rare in the wild in the not too distant future. If, therefore, zoos can breed their own supplies, they will be actually protecting animals from becoming rare. I once asked that famous and most able zoo director, Dr. Ernst Lang of Basel, with which common zoo animals he thought zoos could reasonably expect to become self-supporting within five or ten years so that no further demands need be made on the wild populations. He kindly gave me permission to quote this list, which I had from him 18 months ago:

Great grey kangaroo
Chinchilla
Marmot
Prairie dog
Spiny mouse
Brown bear
Spectacled bear
Collared bear
Leopard
Lion
Puma
Black leopard
European wolf
Serval
Skunk
Tiger
Caracal
Malay tapir
American tapir
Grant's zebra
Beisa antelope
American bison

Fallow deer

Père David's deer

Giraffe

Lesser kudu

Aoudad

Mouflon

Okapi

Roe deer

Reindeer

Thar

Sitatunga

Wild boar

European bison

Pigmy hippopotamus

Hippopotamus

Gorilla

Guereza

Java monkey

Orang utan

Chimpanzee

Black mangabey

Emu

This list suggests that it is now possible for zoos to become selfsupporting in animals which only a few years ago they were lacking themselves. If they can do so it will be an enormous contribution to conservation.

*This has now been done: photographs on plates 9 and 10, following page 116. 
What Must Be Done

What conclusions can we draw from this brief survey of the breeding of rare animals in zoos and elsewhere in captivity?

First, I am convinced that we not only can but must establish a great many more breeding stocks of wild animals, both common and rare in captivity. This is a service which zoos are especially well equipped to perform for the conservation movement. While this is second best to keeping the animals in their natural habitat, we must recognise that, in all too many cases, the best course is no longer open to us. We always have to bear in mind too the need to avoid keeping all our eggs in one basket.

Second, while there are many difficulties to be faced in breeding rare species in zoos, these can and must be overcome. Not all zoos have either the skilled staff, or accommodation, or the funds to undertake these operations, but such human deficiencies can be overcome more readily than the problems of breeding many wild animals in captivity. Smaller zoos have to keep in mind their public, and what their public wants to see. By no means all rare animals are especially interesting to the general public. How many people, for instance, go to a zoo hoping to see tamarau or a Somali wild ass, or even a Père David's deer? It is therefore unreasonable to expect most zoos to keep more than a few rare species, although they can more reasonably be expected to make themselves self-supporting, and even exporters of several common species.

Thirdly, ungulates appear to be the easiest wild animals to breed in captivity, although ducks and many other kinds of birds are also relatively easy. So probably are many rodents, although we know extraordinarily little about most rodents and have scarcely begun to attempt systematic breeding of the rarer species in captivity. Carnivores and primates are generally more difficult, and special attention will need to be paid in the years to come to the problem of establishing regular breeding stocks of the rare species of each. One has only to look at the fine families of gorillas or orang utans here in the San Diego Zoo, or at the Basel Zoo in Switzerland, to realise what can be done. Of course, with aquatic mammals, such as whales and seals, we are at present nowhere near captive breeding, and it will be a sorry day for any species in any one of these groups when captive breeding becomes their last hope. What could we do at present about the blue whale, the largest mammal ever seen on the face of the earth, if this were shown to be the only way of saving it?

Fourthly, a special word of warning is necessary about capture arrangements for rare animals. This is an unfortunate tendency nowadays to suppose that with the invention of drug-darting techniques all has become simple and easy. This is very far from being the case. Drug-darting techniques require a skill and experience that are still very scarce indeed, and the knowledge of the reactions of individual species to drugs is for the vast majority of species non-existent. The 
very greatest care therefore needs to be taken, if the story of one or two recent disastrous attempts is not be repeated. I very much hope that within the next few months an expert on modern darting techniques can be attached to IUCN to supervise all future attempts to use these methods on rare animals. A scheme for such a unit is now being worked on, and anyone who is in a position to help to finance this proposed unit will be a benefactor indeed.

Finally, if ever the International Zoo Federation, which was proposed at the 1964 London Conference, and which must not be confused with the existing IUDZG, gets off the ground, it should co-ordinate the present disconnected efforts to breed more rare species in zoos, and do its best to fill in the gap, and also to operate the proposed system of quotas. The Survival Service Commission of IUCN is always available to supply necessary technical information and to work closely with such a federation. 